June - 2007

\title{
Mobile Usability in Educational Contexts: What have we learnt?
}

\author{
Agnes Kukulska-Hulme \\ The Open University, UK
}

\begin{abstract}
The successful development of mobile learning is dependent on human factors in the use of new mobile and wireless technologies. The majority of mobile learning activity continues to take place on devices that were not designed with educational applications in mind, and usability issues are often reported. The paper reflects on progress in approaches to usability and on recent developments, with particular reference to usability findings reported in studies of mobile learning. The requirements of education are considered as well as the needs of students participating in distance education; discipline-specific perspectives and accessibility issues are also addressed. Usability findings from empirical studies of mobile learning published in the literature are drawn together in the paper, along with an account of issues that emerged in two mobile learning projects based at The Open University, UK, in 2001 and 2005. The main conclusions are: that usability issues are often reported in cases where PDAs have been used; that the future is in scenario-based design which should also take into account the evolution of uses over time and the unpredictability of how devices might be used; and that usability issues should be tracked over a longer period, from initial use through to a state of relative experience with the technology.
\end{abstract}

Keywords: Usability; mobile devices; PDAs; flexible learning; empirical studies; scenario-based design

\section{Introduction}

Mobile learning is proving to be a fertile ground for innovation, but it is important to realise that the success of mobile learning will depend on human factors in the use of the new mobile and wireless technologies. It is only now that the challenges of mobile learning on a larger scale, and with diverse populations of students, are beginning to be understood. This paper draws together what is currently known about user experience, educational requirements, and changing needs in the field of distance learning, and makes suggestions regarding ways of improving the study of mobile learner experience. As Wagner (2005) has pointed out, " . . complicated key controls and difficult-to-read screen presentations will be tolerated only under certain very limited conditions. The rest of us aren't willing to risk having a bad experience. For broad and long-term adoption, the experience really does matter" ( 9 23).

The past few years have witnessed the development of a substantial body of literature reporting pilot projects in learning with mobile devices, and a surge of conferences pertaining to mobile 
learning research. The papers describe mobile systems and software that have either been purpose-built for education or that use off-the-shelf solutions originally intended for business use. In spite of careful designs and preparations on the part of the researchers and practitioners running the projects, issues of usability are known to arise in both situations, preventing learners from engaging fully with their educational tasks.

We have reached the stage in mobile learning research where the considerable body of evidence from various projects and trials can enable us to begin to review in a more global way what has been learnt to date about the usability of mobile devices in education. Admittedly, this is a vast topic and it is not possible to generalise from a range of user experiences that span different technologies, contexts of use, study modes and learning objectives. Nevertheless, there is much to be learnt from being aware of the kinds of usability issues that have arisen in the past. The aim of this paper is two-fold: first, to reflect on progress in approaches to usability and on recent developments in the field, and second, to review usability issues reported in a range of studies of mobile learning. In doing so, it is important to pay attention to the particular needs of students participating in distance education, many of whom would consider themselves to be the original 'mobile learners,' used to carrying their course materials around with them and accessing them in flexible ways. For these students, learning with mobile devices represents another step in the right direction but it also presents some specific challenges.

Accounts of mobile usability issues that pertain to education can be found in many sources, most notably in specialist conference series such as Mlearn, IADIS Mobile Learning, and WMUTE, in themed journal issues and in published case studies (e.g., JISC, 2005). A systematic review of all the available sources would be a valuable exercise; for the purposes of this paper, a number of recurring issues are identified and highlighted as a step towards a systematic review. In the meantime, those who design future studies, those involved in the design and implementation of mobile learning, and the designers of new mobile devices and software can begin to benefit from this evolving collective experience.

As well as examining usability issues reported in specific studies, it is helpful to see them against the background of the state of play in mobile usability and in relation to requirements that might be specific to education. The next two sections address these two aspects in turn.

\section{Mobile Usability}

Mobile usability can be regarded as an emerging specialism within the more general field of usability, which has also been evolving. Human-computer interaction researchers recognize that to produce computer systems with good usability, it is important to understand the psychological, ergonomic, organizational and social factors that determine how people operate. Nielsen (1993) explained usability in terms of a system's overall acceptability, which included its social acceptability and all practical aspects such as reliability, cost, compatibility and usefulness. Subsequently, Preece, Rogers and Sharp (2002) have focused on "creating user experiences that enhance and extend the way people work, communicate, and interact" (p. v). Dix and colleagues (2004) remark that "users no longer see themselves as cogs in a machine . . . it is not sufficient that people can use a system, they must want to use it" (Dix, Finlay, Abowd, \& Beale, 2004, p. 156).

Although researchers in human-computer interaction are forging ahead in developing their visions for helpful and engaging interactions however, the reality for many computer users remains quite different. Influential authors like Cooper (2004) and Nielsen (2005) continue to 
point out the usability shortcomings of current computer software and technology. Shneiderman (2002) has stated that too often computer software is "just too hard to figure out" (p. 24). Yet Shneiderman also believes that new computing methods can produce "more usable, more reliable computer software and user interfaces that yield much improved user experiences" (p. 26).

How do mobile technologies fit into this picture? Are mobile devices bringing us closer to the ideals of usable computing - or distancing us away from them? The user interfaces on mobile devices are often relatively simple, but each manufacturer has a different interface. Devices are also continually being replaced with new models, even before users have got to know them well:

"In many markets, mobile phones have a product life cycle of 12 months or less. Some subscribers are able to put their new phones to immediate and full use. For others, the learning curve is so steep that they move on to a replacement without having learned to exploit the functionality available in the first one" (Gilbert, Sangwan, \& Han Mei lan, 2005, p.1).

Furthermore, hardware limitations that have long been overcome in desktop systems are back on the usability agenda when mobile devices have to be charged regularly, run out of memory, and may be unreliable. New factors have also come into play: the very nature of mobile interaction is that it is frequently interrupted or fragmented, may be highly context-dependent, and takes place in physical environments that may be far from ideal.

In his book devoted to handheld usability, Weiss (2002) remarked on the "general lack of usability on most handheld devices" (p. xiii), whilst Nielsen's verdict on mobile usability in 2003 was that "the latest mobile devices . . . still lack key usability features required for mainstream use" (Nielsen, 2003, p. 1). Recent developments have been characterised by an increasing awareness of contexts of use and how these might evolve. For example, Turel (2006) argues that the emergence of mobile value-added services has introduced a broad range of new use contexts, requiring a new conceptual model of mobile usability. Similarly in relation to mobile data services, Gilbert and colleagues (2005) propose a dynamic perspective of users' out-of-the-box (initial use) experience, embracing differences over time in both the 'external' and 'internal' contexts among users, such as user location, demographics, or lifestyle characteristics.

Current thinking suggests that in mobile learning, user-centred design and attention to contexts of use will lead to better mobile learning usability. Pehkonen and Turunen (2003) have argued that in the case of mobile learning, user-centred design means not only planning learning goals and actions, but also specifying different contexts of use and the requirements of different 'actors,' which might include teachers, students, and even parents. Malliou and Miliarakis (2005), and Evans and Taylor (2005), have also advocated user-centred and scenario-based design. Lessons from the MOBIlearn project (O’Malley, Vavoula, Glew, et al., 2003) include a guideline on usability which suggests observing "the usability requirements of all those involved in the use of the system in any way (learners, teachers, content creators) to assure system acceptability" (p. 32). The guideline elaborates that in designing mobile applications and producing mobile content, it is important to consider the context of use and that the learner should be able to receive personalised information "that is valuable to her in the given context" (O'Malley et al., 2003, p. 32).

With many factors impacting on the usability of mobile devices in education, it is not yet clear whether these user-centred and context-sensitive approaches are the necessary and sufficient ways to ensure a high degree of usability in mobile learning. Those who are involved in designing 
mobile devices have been noticing that "new solutions are utilized in ways that never even occurred to their designers" (Keinonen, 2003, p. 2) - in other words, you cannot fully predict what users will choose to do - and whilst this is not an entirely new phenomenon, the highly personal and portable nature of mobile devices makes it more likely to happen. Besides, uses may become more elaborate over time: Gilbert and colleagues (2005) have drawn attention to the period after initial use of a mobile service, "during which the scope of use expands to fulfil emergent needs" (p. 207).

Another approach to improving usability is to make the user interface or content adaptable to, or by, the user. Making information personally valuable in a given context, as suggested in the MOBIlearn guideline (O'Malley et al., 2003), is one way of adapting to the user. Jäppinen, Ahonen, Vainio, and Tanhua-Piiroinen (2005) have written about the pros and cons of adaptivity in the context of mobile learning: a system that can model the user and automatically regulate and organise its functioning is very appealing, but at the same time this property can make the system less controllable and predictable for the user. Malliou and Miliarakis (2005) put their faith in the adaptability of the mobile system in the MoTFAL project: "it should adapt to the learners' evolving skills and knowledge" (p.122) as part of a set of requirements that are specified to assure its usability.

Returning to the idea that people must want to use a system (see Dix, et al., 2004, above), we can hypothesize that people may acquire a mobile device for a specific purpose but its subsequent use may depend on, and evolve according to, their wants or needs. As noted earlier, they may never discover all the features of their device before moving on to another one, because what they want, or what someone else thinks they want, is a new device. What has not been well researched to date is how people get to know the features and possibilities of their mobile device and its applications over time. How that happens may be determined not only by the individual's effort but by their social networks - and by the extent to which mobile services and content are 'pushed' in their direction by various providers. In educational contexts, where mobile devices may be loaned out to students for a limited period of use, it may also be determined by (non-)ownership of the device. The impact of the education context on mobile usability is explored in more detail in the next section.

\section{Requirements in education}

The reasons underpinning the use of mobile technology in education have been explored by Kukulska-Hulme (2005a), who identified the three main motivations as being: improving access, exploring the potential for changes in teaching and learning, and alignment with wider institutional or business aims. Where the emphasis is on changing teaching and learning, practitioners and researchers are interested in collaborative learning, students' appreciation of their own learning process, consolidation of learning, and ways of helping learners to see a subject differently than they would have done without the use of mobile devices. Just-in-time learning and support for managing learning are also key interests. There is awareness that the new technologies may have a role in reducing cultural and communication barriers, and that they are altering attitudes and patterns of study.

The diversity of reasons for use of mobile technologies in education makes it difficult to make any generalisations about requirements. Nevertheless, there are attempts to characterise these requirements, including in relation to interface design and usability. Nielsen (2001) has remarked that although general usability standards apply equally to e-learning, there are additional considerations, for example the need to keep content fresh in learners' minds so that they do not 
forget things whilst trying to accommodate new concepts. User-centred system design and evaluation have traditionally been driven by the concept of a 'task.' To a certain extent, it is possible to list the kinds of tasks that learners engage in. For example Rekkedal (2002) has suggested that mobile learners in distance education need to be able to perform tasks such as studying the course materials, making notes, writing assignments, accessing a forum, sending and receiving e-mail, and communicating with a tutor. The process of learning, however, is not always easily broken down into tasks, and something like 'studying course materials' is no more than a label that conceals great complexity in how the materials might be studied. Ryan and Finn (2005) have commented on the difficulty of task analysis in relation to mobile learning 'in the field,' in the course of their attempts to define the generic requirements of users who typically operate out in the field (e.g., geologists, archaeologists, journalists, technicians, police). It is also very challenging to design and evaluate tools that support learners' development and interactions with others over time.

Conventional approaches to usability tend to be limited to metrics relating to time taken to complete a task, effort, throughput, flexibility and the user's attitude. Syvänen and Nokelainen (2005) have attempted to go beyond this by combining technical usability criteria (such as accessibility, consistency, reliability) with pedagogical usability components such as learner control, learner activity, motivation and feedback. Kukulska-Hulme and Shield (2004; Shield and Kukulska-Hulme, 2006) have also argued that usability needs to be understood differently when it is being evaluated in the context of teaching and learning, and that the concept of pedagogical usability can be helpful as a means of focusing on the close relationship between usability and pedagogical design. Exploring this concept raises the question of whether there are aspects of pedagogical usability that are discipline-specific; this is examined by Kukulska-Hulme and Shield (2004) in relation to the discipline of language learning. In websites that support language learning, usability might depend on whether the site uses the first or target language, and on its ability to support multimodal and intercultural communication. The ways in which language experts conceptualise user interfaces may also be specific to the culture and sub-cultures of their discipline. These aspects can be hard to quantify and measure, but it does not mean that they are less important.

Discipline-specific perspectives can be identified in a number of mobile learning projects. For example, in the accounting project reported by Roberts, Beke, Janzen, et al. (2003), screen size on the personal digital assistant (PDA) was found to be an important issue because of the particular needs of the discipline, namely data entry and spreadsheet requirements. Polishook's (2005) research into the possibilities for student music composition on PDAs showed that for some individuals, the small, poorly lit low-resolution screens, tiny dialogue boxes, and the need to connect extra wires, stood in the way of productive use for music composition.

Educational activity can sometimes be better understood by system designers when it is seen as an example of a 'rich context' involving different people, the spaces they meet in and the physical artefacts they use (Dix et al., 2004). Collaboration and co-construction of knowledge are nowadays seen as being the defining characteristics of learning, in contrast to cognitive models that previously concentrated more on the individual learner without much consideration of their social and physical environment. In relation to mobile learning, Luckin, du Boulay, Smith et al. (2005) have defined a learning context as an 'ecology of resources' and have shown how technology can link different resource elements within and across learning contexts. 


\section{What have we learnt from empirical studies of mobile learning?}

Many published studies and conference papers mention aspects of usability, either because it was something that was specifically evaluated, or more often, because usability issues arose during a project or trial and seemed worth mentioning. Sometimes testing the usability of a system is a milestone that will determine whether the system is going to be developed further; for example, Hitz and Plattner (2004) state that if the usability tests on their prototype PaperLink system yield satisfactory results, they will proceed to a generic mobile implementation.

Usability is typically considered from the point of view of issues or problems encountered by users, but good usability essentially means that learning can proceed without obstacles and might even be enhanced by the availability of certain features. In Kukulska-Hulme (2005b), a dozen case study accounts of mobile learning were analyzed from a usability perspective and positive aspects were also identified. For example, Trinder, Magill, and Roy's (2005) case study highlighted the advantage of the immediate readiness of PDAs - the fact that they can be switched on and used straight away with no 'boot up' time - making them ideal to grab a few moments' useful working time at times and in locations where even a laptop would not be useful. Trinder and colleagues also claimed that among their learners, the ability to beam items between PDAs encouraged collaboration and communication. In a similar vein, Corlett and Sharples (2005) report the finding that a keyboard was fundamental to making full use of the pen Tablet device. Bradley, Haynes, and Boyle (2005a) give a number of recommendations to make multimedia content on PDAs usable in a local history tour and for learning Java programming, for example increasing the contrast of images and using audio commentary rather than text. Ryan and Finn's (2005) approach - mentioned earlier in relation to field-based learning - also falls into the category of studies that focus on planning-in good usability features rather than eliminating bad ones once they have occurred.

Examples of usability issues that are being reported in the research literature can be summarised under the following headings:

\section{Physical attributes of mobile devices}

Sharples, Corlett, Bull, et al. (2005) report that students expressed discontent about the size and weight of their PDAs, their inadequate memory and short battery life. The memory was considered too small to hold the course resources, additional PDF and media files, added software, games and music files. Bradley, Haynes, and Boyle (2005b) report that limited storage space was an issue on the PDAs used in their project; but they also mention that the size of the PDA was viewed positively by students, who appreciated being able to have a quick look at the PDA while walking, just before an exam, rather than having to carry a book or A4 papers; in those circumstances the small screen of the PDA did not seem to present a problem.

Screen size was identified as the biggest drawback to using PDAs in an outreach project described by Sugden (2005), noting especially that for sight impaired learners "the environment is impossible" (p. 116). In a project reported by Rekkedal (2002), the students "expressed very different views" concerning reading from a small screen. It seems that a small screen may be an issue, but not always. Current opinion is that learners' age may be a factor (van 't Hooft, 2006) and that in the future, virtual screens and keyboards may help overcome the small screen issue (Ally, 2006). 


\section{Content and software applications}

"Learning how to work with a PDA takes more time than people first think, despite the apparent similarity to Windows applications," according to researchers in the Manolo Project (2005). In a slightly different context, Hackemer and Peterson (2005) note that whilst students were comfortable with their handheld's built-in functions, additional applications proved problematic, as most of the available software lacked formal usability assessment and documentation; this resulted in very few students being willing to explore applications in order to understand how they could be used. Smørdal and Gregory's (2005) study showed up problems in cutting and pasting material from one application to another, which limited the usefulness of the PDA as a communication device.

Selecting from a list of options can be a way to make it easier to interact with a mobile device, and, indeed, Cacace and colleagues (Cinque, Crudele, Iannello, \& Venditti, 2004) report that drop-down lists and checklists proved useful in a mobile medical training context. On the other hand, Waycott and colleagues' study in a museum setting (Waycott, Jones, \& Scanlon, 2005) identified that choosing from a list of pre-written messages on the screen of the PDA did not necessarily facilitate peer-to-peer communication. The applications and circumstances of use were very different.

\section{Network speed and reliability}

In Smørdal and Gregory's (2005) study the slow transmission of webpages on GSM-connected PDAs resulted in a negative experience. A JISC case study (2005) in the use of wireless Tablet $P C s$ at a London college identified occasional weak signals and slow access to documents as negative aspects of wireless connectivity within the college. Roberts and colleagues (2003) list wireless network reliability as one of the five key lessons that emerged from a mobile learning pilot project in accounting involving some 300 college students: "For maximum success, the technology has to work reliably. While small screen size and the lack of a keyboard were noted as PDA limitations, they did not generate the level of dissatisfaction among PDA students that the poor wireless WAN network functionality did" (p. 33). On the other hand, with regard to speed, Cinque and colleagues (Cinque, Cacace, Crudele et al., 2005) report that their medical and nursing students tended to prefer a smaller device, with colour display, to a faster one, noting that "usability seems more important than performance" (p. 115).

\section{Physical environment}

Corlett and Sharples (2005) report several usability issues that arose in their pen Tablet project, including difficulties in using the device out of doors due to excessive screen brightness. Bradley, Haynes and Boyle (2005b) noted that amongst their participants there were some concerns about personal security (the risk of being mugged), and about possible radiation from devices using radio frequencies. Manolo Project (2005) case studies in environmental sciences report the need to use rain covers on PDAs outdoors in rainy or humid conditions, and the need to consider the risk of loss and theft of equipment on field trips.

Issues that appear to have a bearing on usability include device ownership and duration of use. In the study reported by Sharples and colleagues (2005) the lack of device ownership meant that since students were required to return their handhelds at the end of the year, they did not want to invest in additional memory modules that would have overcome the memory limitations of their 
PDA. Waycott and colleagues (2005) also comment that in case studies involving PDAs, "where participants were prepared to invest effort in learning how to best use them for their own purpose, they could benefit from this investment as they were using the PDAs over a long period of time" (p. 124).

The impact of usability issues on academic and technical staff are also mentioned in the literature. Luckin et al. (2005) have described the substantial overhead of staff time in terms of technical support, account administration and finding workarounds for features that did not work as required. The Manolo Project (2005) has also emphasized the need for various types of support, including technical support, in its published summary of lessons learned from the project.

Finally, in consideration of learners with disabilities, Dodd, Pearson, and Green (2005) have warned against new teaching methods becoming dependent on inaccessible mobile technology:

Existing devices, exemplified by PDAs, inherently small and used in badly lit, noisy, and moving environments, amplify the demands placed on vision, hearing and mobility skills. . . Current solutions focus on adapting existing commercial products to incorporate impairment-specific devices using Braille keyboards, and screen reading/ magnification technology. Whilst this solves accessibility problems for a narrow band of users, it does not provide the coordinated approach necessary to support disabled users with more than one physical impairment (Dodd, Pearson, \& Green, 2005, p. 49).

This last point has particular implications for distance education, as relatively large proportions of disabled students participate in this form of education. The next section reviews the experiences of distance students in relation to the usability of mobile technologies.

\section{Usability of mobile devices in distance education}

As noted by Ally (2005a), the use of mobile technology in distance education could provide more flexibility for learners, a view that has also been put forward by Rekkedal (2002). Ally also makes the point that mobile learning requires organizational change and careful planning: existing course materials must be converted and new ones developed for delivery on mobile technology; it is necessary to establish a telecommunication infrastructure, train staff and faculty, and so forth.

Most experiences of mobile learning to date relate either to conventional teaching contexts - i.e., in face-to-face teaching in universities, colleges, and schools, or to informal learning in public spaces such as museums and gardens - but there is some experience specifically in distance education. For example, work on mobile learning has been ongoing at the Norwegian Knowledge Institute - NKI Distance Education - for some years now (Fagerberg, Rekkedal, \& Russell, 2002; NKI Distance Education, 2004). Researchers at Birmingham University's Centre for Educational Technology and Distance Learning (subsequently rebranded as CLIC) continue to work on distance and continuing education issues (CLIC, 2006), as do researchers at Athabasca University (McGreal, 2005; McGreal, Cheung, Tin, \& Schafer, 2005; Ally, 2005b).

In this section, the focus is on two projects at The Open University in the UK, both of them concerning the use of mobile devices by students on the Institute of Educational Technology's Masters programme in Online and Distance Education (MAODE). This is a distance learning programme delivered online, making use of Web resources and conferencing. Students enrolled in the programme are typically studying part-time and involved in other professional activities. In 
terms of age, they are mostly in their 40s and come from a variety of cultural backgrounds. The first project summarised here investigated students' use of PDAs that were given to them, whilst the second project investigated their use of their own mobile devices. This parallels developments in the field of mobile learning, in that early projects tended to be based around activities that involved giving or lending mobile devices to students to try out; more recently, due to increased device ownership, there is a growing interest in investigating how mobile devices that are already owned by distance learners could be incorporated into their learning, or how the learners themselves are already using the devices on their own initiative.

\section{PDAs for reading course materials}

During 2001, a study was conducted to evaluate the use of PDA devices by students on the Masters course H802: Applications of IT in Open and Distance Education (Waycott \& KukulskaHulme, 2003; Waycott, Jones \& Scanlon, 2005). The idea was to give students the option of reading some of their course materials on a PDA. Students could choose to read on a PDA or only the print version, or both. As part of this project, cognitive, ergonomic, and affective aspects of PDA use were investigated in some detail (Kukulska-Hulme, 2002).

All 65 students enrolled in the course were supplied with PDAs; most were new to using this type of device. The study aimed to assess the benefits and constraints introduced by PDAs, and examine how this new tool influences students' reading strategies; annotating and note-taking were included in the investigation. WordSmith, a document editor and viewer, was used to present course materials on the PDA. The document viewer mode enabled users to read and search the text in several ways. Participants received the manufacturer manuals, and were also provided with further instructions tailored to their needs. They did not have access to any specific technical support during their use of mobile devices. The model of mobile learning in this project was that of individual learners accessing materials on their individual devices, and to a certain extent, using their own initiative to explore the features and capabilities of the device, although they could share their problems and questions in the online conference.

The conference for this project was opened up to students in the run-up to the distribution of PDAs; this became a focal point for early adopters (i.e., those students who were already users of other handheld computers, or who were immediately interested in the technology). Once the PDAs were distributed, the conference was accessed by a wider circle of students. Numerous hardware, software, synchronisation, and compatibility problems were discussed, and students made comparisons between the PDA and other devices they were familiar with, including their desktop computers. A number of issues emerged during the evaluation period, for example, in relation to reading; skim-reading on a PDA could be slower than skim-reading in print; what students noticed when reading print could also be different from what they noticed when reading on the PDA. When the font was enlarged on the PDA, scanning could be harder. Taking electronic notes and annotating the text could also be difficult on the PDA. Observations that accompanied this study showed that some users had difficulty gripping the very thin stylus and inadvertently pressed buttons at the bottom of the device. It was also noted in this project that the sensitivity of the screen seemed to vary from one PDA to another, and in some cases it was necessary to re-calibrate the screen so that it responded to the stylus. Even with limited use of the PDAs, it was clear that scratches could start to develop on the screen, making it less sensitive and, perhaps, less usable over time.

The project concluded that three main issues needed to be considered in future projects of this kind: (1) usability of the hardware (considering that the PDA used in the project was a relatively 
inexpensive model; the screen contrast was very low and required great concentration); (2) usability of the software (the application used for reading texts was not designed for reading); and (3) usability of the text (the text had not been designed with a PDA in mind).

\section{Survey of how MAODE alumni use mobile devices}

This project ran in 2005 and its participants were registered alumni of the same Masters in Online and Distance Education (MAODE). The alumni had completed at least one-third of the programme, and in some cases all of it. Fifty-seven $(n=57)$ alumni completed an online questionnaire and nine were subsequently interviewed. The purpose was to gather both numerical and qualitative data on the breadth of their use of mobile devices: which did they use, for what activities, and how? Participants were asked whether they had used a mobile phone, smartphone, PDA, and MP3-player (for example, an iPod). For each device, they were asked whether they had used it for teaching, work, learning, social interaction, and entertainment (including quizzes and games). For each activity they selected, they were asked to give an example. Informal uses (with friends, family, or interest groups) could be included when responding about 'teaching' and 'learning.' There was also a catch-all question about any other uses; in addition, participants were asked how often they carried out specific activities with a mobile device, such as reading an ebook, browsing a website, or making a video clip (for more complete accounts of this project, see Kukulska-Hulme \& Pettit, 2006; Pettit \& Kukulska-Hulme, 2006).

A review of the data from the survey shows that the use of PDAs generated the greatest number of spontaneous comments relating to usability. These were not always negative comments. Fortysix percent of the respondents had used a PDA. In relation to uses connected to their work, respondents commented that they used the PDA in preference to a laptop while travelling by train because the battery lasted longer than the one in their laptop, and because a PDA was more comfortable to use in 'airline seats,' that typically do not have a proper table. A separate keyboard was used by three of the respondents. In relation to their use of the PDA for learning, comments included: "trying to download documents to read but finding the screen far too small"; "preferring print rather then the PDA, to read and scribble on on the train"; and "trying to use blogs on the PDA but finding the formatting not good enough." Positive aspects of learning-related usability were using time productively while waiting, and being "always up to date." In relation to social interaction, one respondent regretted not having Wi-fi and another had tried conferencing on the PDA but found it "too clunky, too hard to write on."

Although the data only offered a small selection of comments mentioning aspects related to usability, there was some indication that the PDAs did present some usability issues, particularly in the context of learning. On the other hand, when looked at from the point-of-view of productive use, respondents reported using their PDAs in a rich variety of ways; included in these reports were activities such as brainstorming, mindmapping, reading e-books, downloading academic articles, accessing email, keeping a list of library books to take out, loading copies of software manuals, Web browsing, and use of multiple media (i.e., photos, video, music).

\section{Conclusions}

The paper presented a review of current usability issues in the use of mobile devices in the context of education, almost exclusively in relation to adult learners. In doing so, a broad interpretation of usability has been adopted, encompassing not only technical but also pedagogical considerations, which are often closely intertwined. As we have seen, the field of mobile usability is in a state of evolution, as it reflects and, indeed, takes forward some of the 
developments in the field of usability as a whole. Similarly, there is ongoing discussion of what are the important issues with regard to mobile technology uses in education. In a general review, it is not possible to make definitive statements about usability based on what is often reported in an ad-hoc way in the literature, however some interesting points emerge that can guide our thinking in the future.

The majority of mobile learning activity continues to take place on devices that were not designed with educational applications in mind. It is noticeable that usability issues are often reported where PDAs have been used, which suggests that PDAs might be the object of more usability problems than is the case for mobile phones, for instance. If that is, indeed, the case, then one possible explanation is that devices, such as mobile phones and mp3 players, are more likely to be personally owned by, and hence more thoroughly familiar to, their users; Antoniou and Lepouras (2005) assert that owners' familiarity with their mobile phone avoids many potential usability problems for mobile learning in a museum setting. There is also some evidence to the contrary. For example, it was noted earlier in this paper that users may not know their mobile phone all that well because they are always moving to a newer model; but this may be more applicable to some sectors of the population than others. Another explanation for the extent of reported usability issues in connection with PDAs is that PDAs may feature in more mobile learning studies, as phones and other devices have not so far been researched in learning contexts to quite the same extent (but this is changing). Furthermore, the pace of change in technological developments means that the PDAs used in earlier studies do not necessarily present the same challenges as more recent equipment. Arguably, some usability issues may have been overcome: McGreal and colleagues (2005) take the view that the technological capacity of PDAs "has increased dramatically in the past three years. Screens are bigger and better; systems have more memory; they have more multimedia capabilities; and there are more refined methods for inputting data" (p. 50). It is likely that users' experience with the devices is much improved as a result, although we do not yet have sufficient evidence.

It looks like the future is in scenario-based design, but this should also take into account the evolution of uses over time and the unpredictability of how devices might be used. Disciplinespecific perspectives ought to be brought into play, and accessibility must continue to be considered alongside usability. Findings will always be context-dependent to a considerable extent, but it should be possible to accumulate knowledge about user experience in particular physical environments and situations of use. Some sets of mobile learning guidelines have already been published and they include some mention of usability. Generic requirements for certain types of user are also being elaborated. One final point to make is that rather than testing for usability at just one or two specific points in the life of a project, it would also be beneficial to find ways of tracking usability over a longer period of time, from initial use through to a state of relative experience.

\section{References}

Ally, M. (2005a). Use of Mobile Devices in Distance Education. Paper presented at Mlearn 2005, October 25-28. Cape Town, South Africa.

Ally, A. (2005b). Multimedia information design for mobile devices. In M. Pagani (Ed.) Encyclopedia of Multimedia Technology and Networking. Hershey, PA.: Idea Group.

Ally, M. (2006). Mobile Devices Usability. Posting on the CIDER Mobile Learning SIG forum, June 11, 2006. Retrieved February 14, 2007 from: 
http://cider.athabascau.ca/CIDERSIGs/mobilelearning/mlearndiscussion/talkback/115006 $\underline{6275}$

Antoniou, A., \& Lepouras, G. (2005) Using bluetooth technology for personalised visitor information. Proceedings of the IADIS international Conference on Mobile Learning, June 28-30. Qawra, Malta.

Bradley, C., Haynes, R., \& Boyle, T. (2005a). Design for Multimedia m-Learning: Lessons from two case studies. Paper presented at ALT-C 2005. University of Manchester.

Bradley, C., Haynes, R., \& Boyle, T. (2005b). Adult Multimedia Learning with PDAs: The user experience. Paper presented at Mlearn 2005 Conference, October 25-28. Cape Town, South Africa.

Cacace, F., Cinque, M., Crudele, M., Iannello, G., \& Venditti, M. (2004). The Impact of Innovation in Medical and Nursing Training: a Hospital Information System for students accessible through mobile devices. Paper presented at Mlearn 2004, July 5-6, Rome, Italy. Retrieved February 14, 2007 from: http://www.crudele.it/papers/00269.pdf

Cinque, M., Cacace, F., Crudele, M., Iannello, G., \& Bernaschi, M. (2005) Mobile learning in a hospital environment. Paper pubished in the proceedings of the IADIS international Conference on Mobile Learning, June 28-30. Qawra, Malta.

CLIC (2006). Centre for Learning, Innovation and Collaboration, formerly the Centre for Educational Technology and Distance Learning. University of Birmingham, UK. Retrieved February 14, 2007 from: http://www.clic.bham.ac.uk/

Cooper, A. (2004). The Inmates are Running the Asylum: Why high-tech products drive us crazy and how to restore the sanity. Indianapolis, IN.: Sams Publishing.

Corlett, D., \& Sharples, M. (2005). Tablet technology for informal collaboration in higher education. In J. Attewell \& C. Savill-Smith (Eds.) Mobile Learning Anytime Everywhere: Papers from Mlearn 2004, (pp. 59-61). London: LSDA.

Dix, A., Finlay, J., Abowd, G. D., \& Beale, R. (2004). Human-Computer-Interaction. 3rd edition. Harlow, UK.: Prentice-Hall.

Dodd, R., Pearson, E., \& Green, S. (2005). A systematic approach to mobile accessibility. ALT-C Conference abstracts, September 6-8, 2005. Manchester University.

Evans, D., \& Taylor, J. (2005). The role of user scenarios as the central piece of the development jigsaw puzzle. In: J. Attewell and C. Savill-Smith (Eds.) Mobile Learning Anytime Everywhere: Papers from Mlearn 2004, (pp. 63-66). London: LSDA.

Fagerberg, T., Rekkedal, T., \& Russell, J. (2002). Designing and Trying Out a Learning Environment for Mobile Learners and Teachers. Paper published on the NKI Distance Education - Electronic College. Retrieved February 14, 2007 from: http://www.nettskolen.com/forskning/55/NKI2001m-learning2.html 
Gilbert, A. L., Sangwan, S., \& Han Mei lan, H. (2005). Beyond Usability: The OoBE dynamics of mobile data services markets. Personal and Ubiquitous Computing, 9(4), 198-208.

Hackemer, K., \& Peterson, D. (2005). University of South Dakota Palm Initiative. In A. Kukulska-Hulme \& J. Traxler (Eds.) Mobile Learning: A handbook for educators and trainers (pp. 157-163). London: Routledge.

Hitz, M., \& Plattner, S. (2004). PaperLinks - Linking printouts to mobile devices. In J. Attewell \& C. Savill-Smith (Eds.) Mobile Learning Anytime Everywhere - a book of papers from MLEARN 2004 (pp. 105-108). London: LSDA.

Jäppinen, A., Ahonen, M., Vainio, T., \& Tanhua-Piiroinen, E. (2005). Adaptive Mobile Learning Systems: The essential issues from the design perspective. In J. Attewell \& C. SavillSmith (Eds.) Mobile Learning Anytime Everywhere - a book of papers from MLEARN 2004 (pp. 109-111). London: LSDA.

JISC (2005). Case Studies of Innovative Practice: Wireless and Mobile Learning. Project led by Agnes Kukulska-Hulme at The Institute of Educational Technology, The Open University, UK. Retrieved February 14, 2007 from:

http://www.jisc.ac.uk/whatwedo/programmes/elearning_innovation/eli_oucasestudies.asp $\underline{\mathrm{x}}$

Keinonen, T. (2003). Introduction: Mobile distinctions. In C. Lindholm, T., Keinonen, \& H., Kiljander (Eds.) Mobile Usability: how Nokia changed the face of the mobile phone (pp. 1-8). New York: McGraw-Hill.

Kukulska-Hulme, A. (2002). Cognitive, ergonomic, and affective aspects of PDA use for learning. Proceedings of 2002 European Workshop on Mobile and Contextual Learning, June 20-21. University of Birmingham.

Kukulska-Hulme, A. (2005a). Current uses of wireless and mobile learning - Landscape study on the use of mobile and wireless technologies for teaching and learning in the Post-16 sector. JISC-funded project. Retrieved February 14, 2007 from: http://www.jisc.ac.uk/uploaded_documents/Current\%20Uses\%20FINAL\%202005.doc

Kukulska-Hulme, A. (2005b). Mobile Usability and User Experience. In A. Kukulska-Hulme \& J. Traxler, J. (Eds.) Mobile Learning: A handbook for educators and trainers (pp. 45-56). London: Routledge.

Kukulska-Hulme, A. \& Pettit, J. (2006). Practitioners as innovators: emergent practice in personal mobile teaching, learning, work and leisure. Paper submitted to the 2006 Mlearn Conference, October 22-25. Banff, Canada.

Kukulska-Hulme, A., \& Shield, L. (2004). Usability and Pedagogical Design: Are language learning websites special? Paper presented at ED-MEDIA 2004 World Conference on Educational Multimedia, Hypermedia and Telecommunications. June 22-26. Lugano, Switzerland. Retrieved February 14, 2007 from: http://www.aace.org/DL/index.cfm?fuseaction=ViewPaper\&id=16072 
Luckin, R., Brewster, D., Pearce, D., du Boulay, B., \& Siddons-Corby, R. (2005). Whether it's mlearning or e-learning, it must be ME learning. In A. Kukulska-Hulme \& J. Traxler (Eds.) Mobile Learning: A handbook for educators and trainers (pp. 116-124). London: Routledge.

Luckin, R., du Boulay, B., Smith, H., Underwood, J., Fitzpatrick, G., Holmberg, J., Kerawalla, L., et al. (2005). Using Mobile Technology to Create Flexible Learning Contexts. In A. Jones, A. Kukulkska-Hulme, \& D. Mwanza (Eds.) Portable Learning: Experiences with Mobile Devices. Journal of Interactive Media in Education 22. Retrieved February 14, 2007 from: http://jime.open.ac.uk/2005/22/

Malliou, E., \& Miliarakis, A. (2005). The MOTFAL Project: Mobile technologies for ad hoc learning. In J. Attewell \& C. Savill-Smith (Eds.) Mobile Learning Anytime Everywhere: Papers from Mlearn 2004 (pp. 119-122). London: LSDA.

Manolo Project (2005). Guidelines for Integrating e-, w-, and m-Learning. Project deliverables lessons learned. Retrieved February 14, 2007 from: http://www.spinlab.vu.nl/manolo/

McGreal, R. (2005). Mobile devices and the future of free education. Paper presented at the ICDE World Conference 2005, October 24-28. New Delhi: International Council for Distance Education.

McGreal, R., Cheung, B., Tin, T., \& Schafer, S. (2005) The Athabasca University Digital Reading Room: Library resources for mobile students. Paper published in the proceedings of the 2005 IADIS International Conference on Mobile Learning, June 2830. Qawra, Malta.

Nielsen, J. (1993). Usability Engineering. Boston MA.: Academic Press.

Nielsen, J. (2001, January 16). Jakob Nielsen on e-learning. Article published on Elearning Post. Retrieved February 14, 2007 from: http://www.elearningpost.com/articles/archives/jakob nielsen on e learning/

Nielsen, J. (2003, August 18). Mobile Devices: One generation from useful. Alertbox posting on useit.com: Jakob Nielsen's Website. Retrieved February 14, 2007 from: http://www.useit.com/alertbox/20030818.html

Nielsen, J. (2005, October 3). Top Ten Web Design Mistakes of 2005. Posting in Jakob Nielsen's Alertbox. Retrieved February 14, 2007 from: http://www.useit.com/alertbox/designmistakes.html

NKI Distance Education (2004, October). Mobile Learning - The Next Generation of Learning, White Paper. Retrieved February 14, 2007 from: http://whitepapers.silicon.com/0,39024759,60133005p-39000592q,00.htm

O’Malley, C., Vavoula, G., Glew, J.P., Taylor, J., Sharples, M., \& Lefrere, P. (2003). MOBIlearn WP4 - Guidelines for Learning/Teaching/Tutoring in a Mobile Environment. Retrieved February 14, 2007 from: http://www.mobilearn.org/download/results/guidelines.pdf 
Pehkonen, M., \& Turunen, H. (2003). Preliminary guidelines for the design of the mobile learning activities and materials. In EUROPRIX Scholars Conference, Conference Papers and Presentations, November 13-14. Tampere, Finland: European Academy of Digital Media, MindTrek Association. Retrieved February 14, 2007 from: http://www.mindtrek.org/liitetiedostot/materiaalit editori/75.doc

Pettit, J., \& Kukulska-Hulme, A. (2006). Going with the grain - mobile devices in practice. Paper submitted to the ASCILITE 2006 Conference, December 3-6. Sydney, Australia.

Polishook, M. (2005). Handheld Composing: Reconceptualizing artistic practice with PDAs. In A. Kukulska-Hulme \& J. Traxler, (Eds.) Mobile Learning: A handbook for educators and trainers (pp. 133-138). London: Routledge.

Preece, J., Rogers, Y., \& Sharp, H. (2002). Interaction Design: Beyond human-computer interaction. New York: John Wiley.

Rekkedal, T. (2002). M-Learning for PDAs: Enhancing the flexibility of distance education. Powerpoint presentation delivered to Ericsson Education, November 22. Dublin, Ireland. Retrieved February 14, 2007 from: http://learning.ericsson.net/mlearning2/project_one/presentation/torstein1911.ppt

Roberts, J., Beke, N., Janzen, K., Mercer, D., \& Soetaert, E. (2003). Harvesting Fragments of Time: Mobile learning pilot project. Final Report. McGraw-Hill Mobile Learning Pilot Project Consortium, May 1. Toronto, Canada.

Ryan, P., \& Finn, E. (2005) Field-based mLearning: Who wants what? Proceedings of the IADIS International Conference on Mobile Learning. June 28-30. Qawra, Malta.

Sharples, M., Corlett, D., Bull, S., Chan, T., \& Rudman, P. (2005). The Student Learning Organiser. In A. Kukulska-Hulme \& J. Traxler (Eds.) Mobile Learning: A Handbook for Educators and Trainers (pp. 139-149). London: Routledge.

Shield, L., \& Kukulska-Hulme, A. (2006). Are language learning websites special? Towards a research agenda for discipline-specific usability. Journal of Educational Multimedia and Hypermedia, 15(3), 349-369.

Shneiderman, B. (2002). Leodardo's Laptop: Human needs and the new computing technologies. Cambridge, MA.: MIT Press.

Smørdal, O., \& Gregory, J. (2005). KNOWMOBILE: mobile opportunities for medical students. In A. Kukulska-Hulme \& J. Traxler (Eds.) Mobile Learning: A handbook for educators and trainers (pp. 99-105). London: Routledge.

Sugden, D. (2005). Exploring the physical frontiers of e-learning. The use of personal digital assistants (PDAs) in outreach centres. ALT-C 2005 Research Proceedings, September 68, University of Manchester. 
Syvänen, A., \& Nokelainen, P. (2005). Evaluation of the technical and pedagogical mobile usability. In J. Attewell \& C. Savill-Smith (Eds.) Mobile Learning Anytime Everywhere: A book of papers from MLEARN 2004 (pp. 191-195). London: LSDA.

Trinder, J., Magill, J., \& Roy, S. (2005). Expect the Unexpected: Practicalities and problems of a PDA project. In A. Kukulska-Hulme \& J. Traxler (Eds.) Mobile Learning: A handbook for educators and trainers (pp. 92-98). London: Routledge.

Turel, O. (2006). Contextual effects on the usability dimensions of mobile value-added services: a conceptual framework. International Journal of Mobile Communications, 4(3), 309-332.

van 't Hooft, M. (2006). Usability issues. Posting on the CIDER Mobile Learning SIG forum, May 26, 2006. Retrieved February 14, 2007 from:

http://cider.athabascau.ca/CIDERSIGs/mobilelearning/mlearndiscussion/talkback/114865 $\underline{6719}$

Wagner, E. D. (2005). Enabling Mobile Learning. EDUCAUSE Review, 40(3), 40-53. Retrieved February 14, 2007 from: http://www.educause.edu/apps/er/erm05/erm0532.asp?bhcp=1

Waycott, J., \& Kukulska-Hulme, A. (2003). Students’ Experiences with PDAs for Reading Course Materials. Personal and Ubiquitous Computing, 7(1), 30-43.

Waycott, J., Jones, A., \& Scanlon, E. (2005). PDAs as Lifelong Learning Tools : An activity theory based analysis. Learning, Media and Technology, 30(2), 107-130.

Weiss, S. (2002). Handheld Usability. Chichester, UK.: John Wiley.

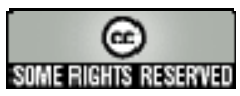

